\title{
PALATALLY DISPLACED MAXILLARY LATERAL INCISORS MAYBE A CAUSATIVE FACTOR OF MANDIBULAR DEFICIENCY
}

\author{
Fady Hussein Fahim* and Dina Osman ElAbbasy*
}

\begin{abstract}
Introduction: Several factors play a role in the etiology of skeletal Class II malocclusion. Displaced maxillary incisors might have a hindering effect on mandibular growth potential.

Aim of the study: The aim of this cross-sectional study was to evaluate the influence of palatally displaced maxillary incisors on mandibular growth in a group of Egyptian patients.

Subjects and Methods: The sample consisted of the digital lateral cephalometric radiographs of untreated 24 patients (12 females and 12 males) with age range of 15-30 years and a mean age of 22.4 years during the permanent dentition stage. The radiographs were selected from the patient database of private practice in Cairo. The sample was divided into 2 groups each consisting of 12 patients. Group A had palatally displaced maxillary lateral incisors without crossbite. Group B had palatally displaced maxillary lateral incisors with crossbite. Linear and angular cephalometric measurements (ANB \& Witts appraisal) were used to assess the anteroposterior skeletal malocclusion and the position of the apical bases of the jaws in both groups. Independent samples t-test was performed to compare the results between the two groups.
\end{abstract}

Results: Cephalometric measurements revealed statistically significant differences between groups A and B showing a mild skeletal Class II malocclusion with a retrognathic mandible in Group A (mean ANB $\left.=4.4^{\circ} \pm 1.85\right)$, (mean Witts $\left.=1.85 \mathrm{~mm} \pm 3.22\right)$ while Group B had skeletal Class I pattern with mild skeletal Class III tendency (mean $\mathrm{ANB}=0.8^{\circ} \pm 1.88$ ), (mean Witts= $-2.5 \mathrm{~mm} \pm 2.33)$.

Conclusions: Palatally displaced maxillary lateral incisors without crossbite cause restraining effect on normal mandibular growth which results in mild skeletal Class II with mandibular deficiency. However, palatally displaced maxillary lateral incisors that are in crossbite have no restraining effect on mandibular growth which results in normal to slightly excessive mandibular growth. This can be used as a tool for early prediction of mandibular growth pattern that necessitates immediate intervention.

\footnotetext{
* Lecturers of Orthodontics, Faculty of Dentistry, Cairo University
} 


\section{INTRODUCTION}

Malocclusion is a manifestation of an interplay of both genetic and environmental factors on the development of the orofacial complex (Mossey, 1999). Skeletal Class II malocclusion is one of the most common dentofacial discrepancies with $27 \%$ prevalence according to Edward Angle (Proffit and Fields, 2014). It occurs due to increased maxillary growth, decreased mandibular growth or a combination of both. Mandibular deficiency has been documented as the most frequent cause constituting around $75 \%$ of the cases (McNamara, 1981).

Depending on the maxillary incisors position, two types of skeletal Class II malocclusion exist: Class 2 division I and Class 2 division II. Environmental factors which contribute to the development of skeletal Class II malocclusion include trauma, muscle imbalance, soft tissue such as tongue habits and prolonged sucking and mouth breathing due to allergies or enlarged adenoids. (King et al, 1990). The clinical features associated with skeletal Class 2 division I are proclination of maxillary incisors, increased overjet, narrow maxillary arch, short upper lip which results in absence of lip seal and deficient mandible with receded chin. On the other hand, class 2 division 2 is characterized by lingual inclination of the maxillary central incisors which are overlapped by the maxillary lateral incisors, deep bite and normal mandibular size (Patel et al, 2016).

Special attention has been given to the identification and correction of the environmental factors that cause incompatibility in the development of the face and jaws. Timely intervention can be crucial to redirect the growth in a favourable direction to help establish a good occlusion and avoid complexity of treatment later. However, limited literature has been available regarding the influence of the dentoalveolar complex on the establishment of skeletal malocclusion. To our knowledge the only aspect that has been tackled was an association between mandibular retrusion and maxillary dental arch lateral constriction which if corrected can lead to spontaneous correction of skeletal Class II (Wendling, 1997). Whether the anteroposterior position of maxillary teeth can have an effect on the mandibular growth potential or not is a subject that has not been questioned.

Palatal displacement of maxillary lateral incisors can occur in association with an anterior crossbite with the lower dentition or without an anterior crossbite. This retrospective study was designed to evaluate whether the palatal displacement of these teeth can have an influence on sagittal mandibular growth.

\section{MATERIAL AND METHODS}

A careful selection was conducted from the patients' database of a private practice located in Cairo, Egypt comprising 24 adult patients with a mean age of 22.4 (age range 15-30 years)and equal number of males and females.

Patients fulfilling the following criteria have been included in the study:

- No past history of orthodontic treatment

- No history of dental anomalies or craniofacial syndromes

- No systemic diseases or hormonal imbalances

- No missing teeth (except permanent $3^{\text {rd }}$ molars)

- Full set of permanent dentition

- Palatally displaced maxillary lateral incisors

- Full orthodontic records including good quality photos and radiographs

Based on the position of the maxillary lateral incisors, the sample was divided into 2 groups:

Group A: palatally displaced maxillary lateral incisors without crossbite $(\mathrm{n}=12)$ (Figure 1)

Group B: palatally displaced maxillary lateral incisors with crossbite (at least one maxillary lateral incisor in crossbite) $(\mathrm{n}=12)$ (Figure 2)

On the pretreatment lateral cephalograms of each study group, the anatomic tracings and location of 
the skeletal landmarks were manually completed by a single investigator to avoid interobserver variation then linear and angular measurements were performed. Two weeks later, the same investigator repeated all the measurements again to analyze the error and determine the correlation coefficient.

The angular and linear cephalometric measurements used for cephalometric analysis were:

SNA: The angle formed by points Sella, Nasion and A point and describes the sagittal position of the maxilla relative to the anterior cranial base
SNB: The angle formed by points Sella, Nasion and $\mathrm{B}$ point and describes the sagittal position of the mandible relative to the anterior cranial base

ANB: angle formed between points A, Nasion and $\mathrm{B}$ point indicating the skeletal relationship between the maxilla and the mandible.

Witts appraisal: The linear distance between the perpendicular projections of points $\mathrm{A}$ and $\mathrm{B}$ over the functional occlusal plane.
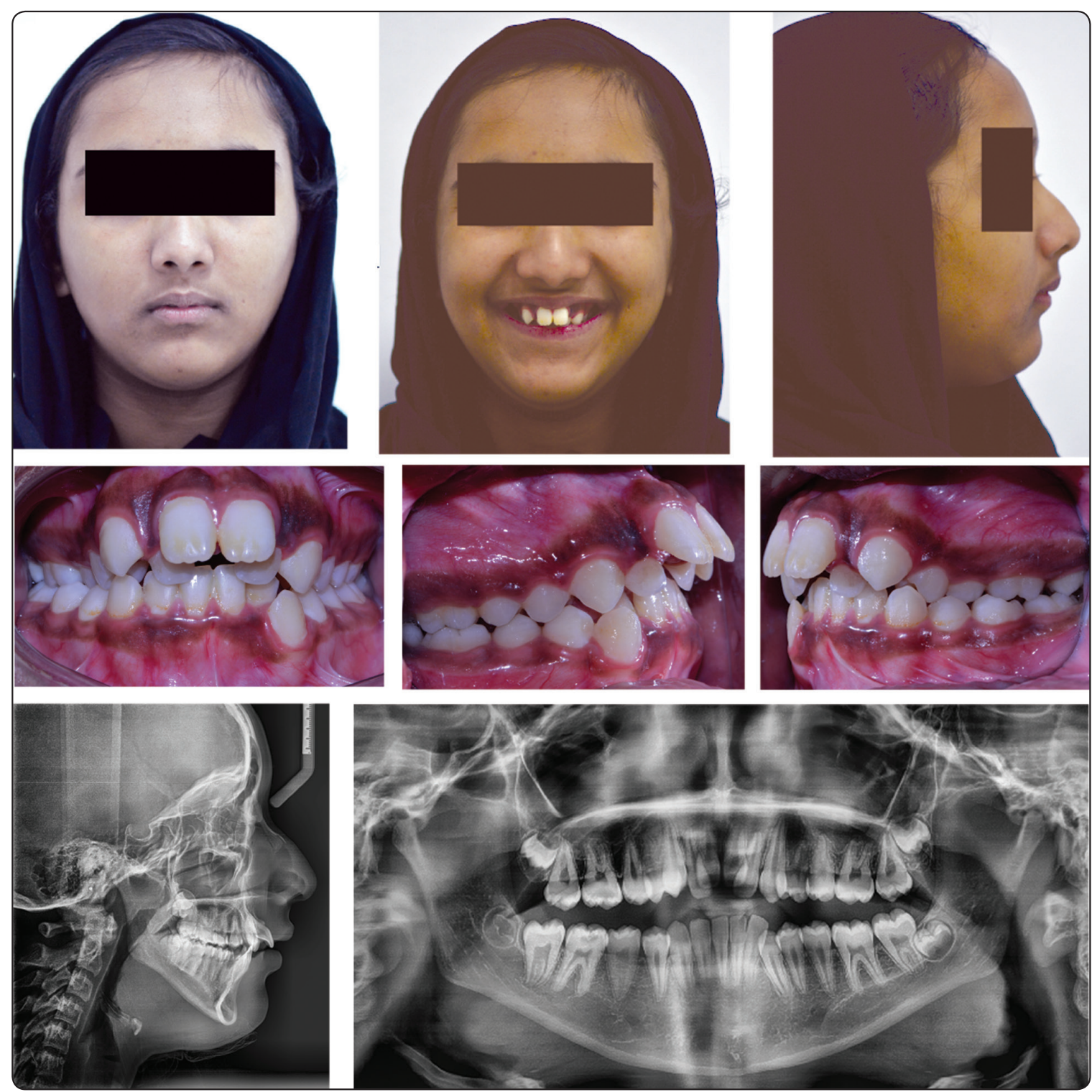

Fig. (1) Orthodontic photos and radiographs of a patient with palatally erupted maxillary lateral incisors without crossbite 


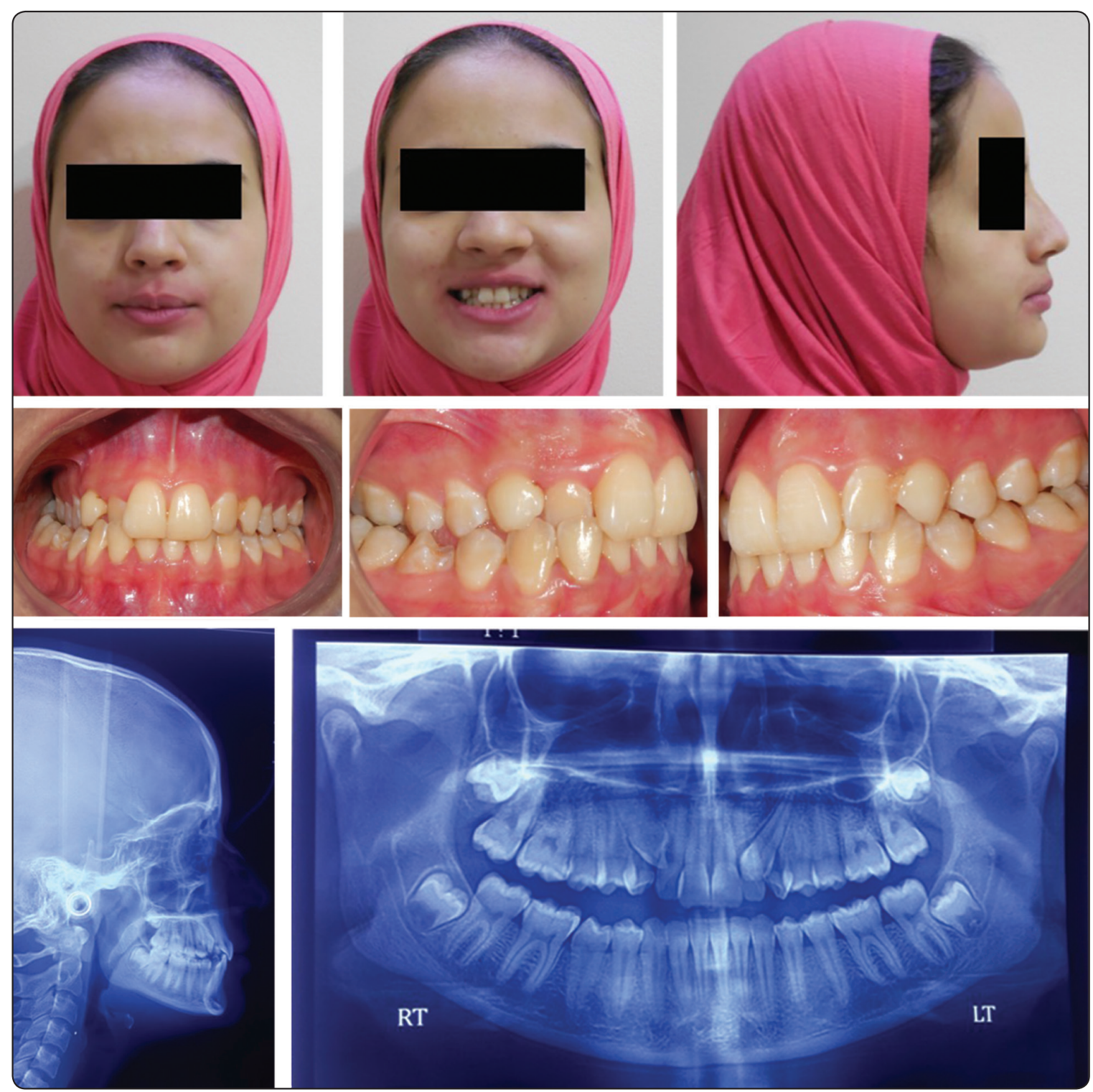

Fig. (2) Orthodontic photos and radiographs of a patient with palatally erupted maxillary lateral incisors with crossbite

\section{Statistical analysis:}

All Data were collected, tabulated and subjected to statistical analysis. Statistical analysis was performed by SPSS in general (version 17), while Microsoft office Excel was used for data handling and graphical presentation.

Quantitative variables were described by the Mean, Standard Deviation (SD), the Range (Minimum - Maximum), Standard Error (SE) and 95\% confidence interval of the mean.
Qualitative categorical variables were described by proportions and Percentages.

Shapiro-Wilk test of normality was used to test normality hypothesis of all quantitative variables for further choice of appropriate parametric and non parametric tests. Mostly the variables were found normally distributed allowing the was used of parametric tests. Independent samples t test for comparing the difference (Post-Pre) between the two groups. Chi-squared test was applied for 2 by 2 contingency table . 
Significance level was considered at $\mathrm{P}<0.05$ (S); while for $\mathrm{P}<0.01$ was considered highly significant (HS). Two Tailed tests were assumed through out the analysis for all statistical tests.

\section{RESULTS:}

The intraclass Correlation Coefficient (ICC) displayed excellent reliability (0.9).

Comparison between the two study groups revealed statistically significant differences between the angular and linear measurements ANB and Witts appraisal at $(\mathrm{P}<.001)$ denoting skeletal class II with mild mandibular deficiency in Group $\mathrm{A}$ (mean value of $\mathrm{ANB}=4.75^{\circ}, \mathrm{SD} \pm 1.96$ and Witts appraisal $=2.46 \mathrm{~mm}, \mathrm{SD} \pm 3.39)$ and skeletal Class I with normal/slightly increased mandibular growth in Group B with mild tendency towards skeletal Class III (mean value of $\mathrm{ANB}=1^{\circ}, \mathrm{SD} \pm 1.86$ and Witts appraisal $=-2.50, \mathrm{SD} \pm 2.02)$. Thus Group A had statistically highly significant mean values of ANB and Witts compared to Group B. (Tables 1,2). The distribution of the skeletal malocclusion type between Group A and B showed highly significant differences (Table 3).

TABLE (1) Independent samples t-test for comparing mean ANB angle of the two study groups

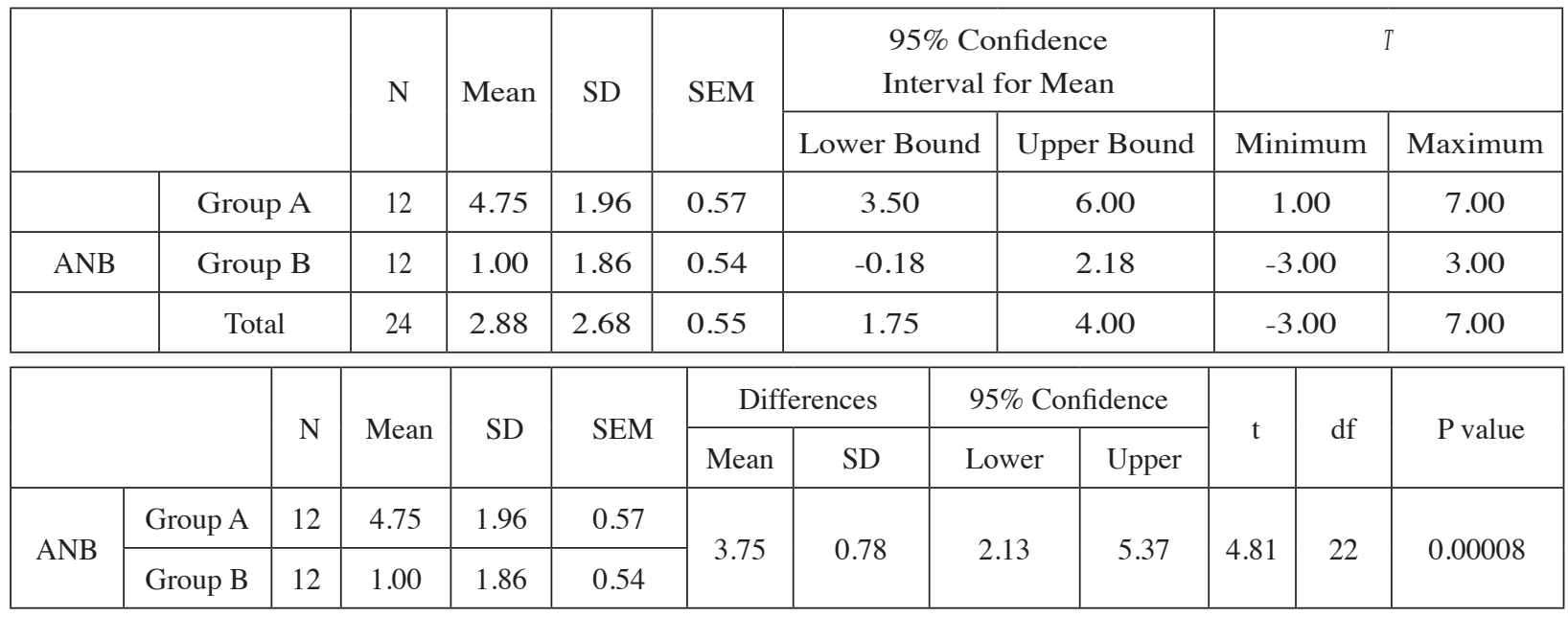

$P>.05$ Non Significant

TABLE (2) Independent samples t-test for comparing mean Wits appraisal of the two study groups

\begin{tabular}{|c|c|c|c|c|c|c|c|c|c|c|c|c|c|}
\hline & & & \multirow{2}{*}{$\mathrm{N}$} & \multirow{2}{*}{ Mean } & \multirow{2}{*}{ SD } & \multirow{2}{*}{ SEM } & \multicolumn{4}{|c|}{$95 \%$ Confidence } & \multirow{2}{*}{\multicolumn{2}{|c|}{ Minimum }} & \multirow{2}{*}{ Maximum } \\
\hline & & & & & & & \multicolumn{2}{|c|}{ Lower Bound } & \multicolumn{2}{|c|}{ Upper Bound } & & & \\
\hline & \multicolumn{2}{|c|}{ Group A } & 12 & 2.46 & 3.39 & 0.98 & \multicolumn{2}{|c|}{0.30} & & 4.61 & \multicolumn{2}{|c|}{-3.00} & 7.00 \\
\hline \multirow[t]{2}{*}{ Witts } & \multicolumn{2}{|c|}{ Group B } & 12 & -2.50 & 2.02 & 0.58 & \multicolumn{2}{|c|}{-3.79} & & -1.21 & \multicolumn{2}{|c|}{-6.00} & 1.00 \\
\hline & \multicolumn{2}{|c|}{ Total } & 24 & -0.02 & 3.73 & 0.76 & \multicolumn{2}{|c|}{-1.59} & & 1.55 & \multicolumn{2}{|c|}{-6.00} & 7.00 \\
\hline & & & & & & \multicolumn{2}{|c|}{ Differences } & \multicolumn{3}{|c|}{$95 \%$ Confidence } & & & \\
\hline & & $\mathrm{N}$ & Mean & SD & SEM & Mean & SD & Lor & & Upper & $\mathrm{t}$ & df & $\mathrm{P}$ value \\
\hline \multirow[t]{2}{*}{ Witts } & Group A & 12 & 2.46 & 3.39 & 0.98 & \multirow{2}{*}{4.96} & \multirow{2}{*}{1.14} & \multirow{2}{*}{\multicolumn{2}{|c|}{2.59}} & \multirow{2}{*}{7.32} & \multirow{2}{*}{4.35} & \multirow{2}{*}{22} & \multirow{2}{*}{0.00026} \\
\hline & Group B & 12 & -2.50 & 2.02 & 0.58 & & & & & & & & \\
\hline
\end{tabular}


TABLE (3) Distribution of the skeletal malocclusion between the two study groups

\begin{tabular}{|c|c|c|c|c|c|c|c|}
\hline & \multicolumn{2}{|c|}{ Class I } & \multicolumn{2}{c|}{ Class II } & \multirow{2}{*}{ Total } & \multirow{2}{*}{ P value } \\
\cline { 2 - 6 } & Frequency & Percent & \multicolumn{2}{c|}{ Frequency Percent } & & \multirow{2}{*}{24.00} & \multirow{2}{*}{0.00000} \\
\hline Group A & 0 & $0.0 \%$ & 12 & $100.0 \%$ & 12 & 12 & \\
\hline Group B & 12 & $100.0 \%$ & 0 & $0.0 \%$ & 24 & & \\
\hline Total & 12 & $50.0 \%$ & 12 & $50.0 \%$ & 24 \\
\hline
\end{tabular}

\section{$P<.001$ Highly Significant}

Regarding gender and age, there were no statistically significant differences of the distribution of gender and age between the two groups (Tables 4,5).

TABLE (4) Chi-squared test for gender distribution between the two study groups

\begin{tabular}{|c|c|c|c|c|c|c|c|}
\hline & \multicolumn{2}{|c|}{ Males } & \multicolumn{2}{c|}{ Females } & \multirow{2}{*}{ Total } & \multirow{2}{*}{ Chi- squared } & \multirow{2}{*}{ P value } \\
\cline { 2 - 5 } & Frequency & Percent & Frequency & Percent & & \multirow{2}{*}{0.67} & 0.41422 \\
\hline Group A & 5 & $41.7 \%$ & 7 & $58.3 \%$ & 12 & 12 & \\
\hline Group B & 7 & $58.3 \%$ & 5 & $41.7 \%$ & 24 & & \\
\hline Total & 12 & $50.0 \%$ & 12 & $50.0 \%$ & & \\
\hline
\end{tabular}

$P>.05$ Non Significant

TABLE (5) Independent samples $t$ test for comparing mean age of the two study groups

\begin{tabular}{|c|c|c|c|c|c|c|c|c|c|c|c|c|}
\hline & & \multirow[t]{2}{*}{$\mathrm{N}$} & \multirow[t]{2}{*}{ Mean } & \multirow[t]{2}{*}{ SD } & \multirow[t]{2}{*}{ SEM } & \multicolumn{2}{|c|}{ Differences } & \multicolumn{2}{|c|}{$\begin{array}{c}95 \% \text { Confidence Interval } \\
\text { of the Difference }\end{array}$} & \multirow[t]{2}{*}{$\mathrm{t}$} & \multirow[t]{2}{*}{ df } & \multirow[t]{2}{*}{$P$ value } \\
\hline & & & & & & Mean & $\mathrm{SD}$ & Lower & Upper & & & \\
\hline \multirow{2}{*}{ Age } & Group A & 12 & 22.37 & 4.30 & 1.24 & \multirow{2}{*}{-0.13} & \multirow{2}{*}{1.77} & \multirow{2}{*}{-3.81} & \multirow{2}{*}{3.54} & \multirow{2}{*}{-0.08} & \multirow{2}{*}{22} & \multirow{2}{*}{0.94069} \\
\hline & Group B & 12 & 22.50 & 4.37 & 1.26 & & & & & & & \\
\hline
\end{tabular}

$P>.05$ Non Significant

\section{DISCUSSION}

The etiology of class II malocclusion ranges between skeletal, dental factors, soft tissues, and oral habits (Rita and Sadat, 2014). Accurate diagnosis and treatment planning are crucial for the success of the orthodontic therapy and the choice of the right treatment protocol. Timely intervention is also imperative for reaching successful results by maximizing the benefit obtained from normal growth potential.
It is well documented that soft tissue or habitual factors are etiological elements that cause malocclusion (King et al, 1990). However, a number of recent studies assumed that craniofacial morphology is genetically predetermined and that it is frequently the cause behind the development of a habit, such as mouth breathing or lip biting, not the other way round (Patel et al, 2016). Accordingly it is very important to identify the contribution of all the factors towards the development of the malocclusion. This helps to shape the expectations 
and prognosis regarding the treatment outcome. Another example is incompetent lips which is believed to affect the balance between the labial and lingual pressure on the teeth and are believed to aid the development of skeletal Class II division 1 malocclusion. However, if we look at it from a genetic perspective, we can safely assume that the underlying craniofacial morphology or excessive maxillary and deficient mandibular growth have led to lip incompetency and subsequently worsened the malocclusion (Ionescu et al, 2008). Accordingly it is very important to identify the contribution of all the factors towards the development of the malocclusion. This helps to shape the expectations and prognosis regarding the treatment outcome as well as remove the causative factor of the malocclusion if possible.

In this study, there were statistically significant differences between angle ANB and Witts appraisal for both Groups A and B with mean values of $\left(4.75^{\circ}, 2.46 \mathrm{~mm}\right)$ in Group A respectively and $\left(1^{\circ}\right.$, $-2.50 \mathrm{~mm}$ ) in Group B. Hence Groups Aand B had different skeletal patterns with mild skeletal Class II in Group A and skeletal Class I with slight tendency for skeletal Class III in Group B.

Previous studies have found a clear correlation between transversely deficient upper arches and the mandibular retrusion associated with skeletal Class II. (Kirjavainen et al, 1997; Lima \& Lima, 2000 and McNamara, 2002). Tollaro et al, 1996 examined a number of Class II malocclusions and observed a transverse maxillary constriction of 3 to $5 \mathrm{~mm}$ with jaws closed in centric occlusion and no posterior crossbites evident. This discrepancy was obvious when the patients postured their mandible anteriorly. Following correction of the transverse maxillary discrepancy by slow or rapid palatal expansion, occlusal interferences are removed and the mandible is believed to be freed with more potential for sagittal growth (Starnbach et al, 1966 and Marshall et al, 2005). Vargervik, 1979 indicated that at least $2-4 \mathrm{~mm}$ of maxillary intermolar width increase is necessary to correct the maxillary constriction. These problems, which are a combination of skeletal and dental factors, are not self-correcting during the mixed dentition period and hence require intervention (Baccetti et al, 1997 and Franchi et al, 2005). However, others (Garib et al, 2007 and Volk et al, 2010) reported no significant mandibular sagittal changes in response to rapid palatal expansion. Furthermore (Sarver, 1989 and Wertz, 1970) even found that maxillary expansion could worsen a Class II malocclusion, since the maxilla might be displaced downward and forward, and the mandible rotates downward and backword. A randomized control trial by Lione et al, 2017 concluded that orthopedic expansion did not influence the sagittal relationship of Class II cases and that larger samples are essential in additional studies to exclude individual variations in the response of the mandible to maxillary expansion.

In our study, it seemed that the reason for palatal displacement of the maxillary lateral incisors without crossbite is mostly related to a transverse maxillary deficiency with a constricted upper arch. This transverse deficiency leads to lack of space which results in palatal displacement of the incisors. The backward position of the upper lateral incisors is believed to cause a restraining effect on forward mandibular growth. Hence these cases may also benefit from palatal expansion which removes functional interferences and release the mandible while at the same time help create space for the alignment of the incisors and hence remove the restraining barrier of mandibular growth (Dewel, 1964 and Guest et al, 2010). This helps reduce the severity of the skeletal jaw discrepancy. It can also avoid the need for future comprehensive treatment in either arches. This is in agreement with the hypothesis that the majority of Class II division 1 cases have functional retrusion of the mandible due to reduced maxillary intercanine width (Haas, 1970). Rapid palatal expansion can be performed using a variety of appliances such as Haas-type expander or Hyrax. It is advisable to overexpand the maxilla so that the upper molar palatal cusps 
occlude with the lower molar buccal cusps). In these cases, the expanded maxilla appears to have the role of an endogenous functional appliance that promotes the mandible to be released and postured forward (Haas et al, 2000; McNamara Jr, 2002 and Lima Filho \& De Oliveira Ruellas, 2007).

Other treatment modalities that can be implemented include extraction of the maxillary primary canines in crowded upper arches to allow alignment of the upper lateral incisors. Another option is the usage of $2 \times 4$ appliance to align and level the palatally displaced maxillary lateral incisors.

On the other hand, it was observed in our study that the palatally displaced maxillary lateral incisors in crossbite were not associated with a reduced transpalatal width, but the transverse dimensions of the upper arch were normal. This did not affect mandibular growth and the mandible grew normally in a sagittal direction. This confirms the theory that lateral constriction of the maxillary arch is also a contributing factor in preventing normal mandibular growth.

\section{CONCLUSIONS}

Palatally displaced maxillary lateral incisors without crossbite cause restraining effect on normal mandibular growth which results in mild skeletal Class II with mandibular deficiency. However, palatally displaced maxillary lateral incisors that are in crossbite have no restraining effect on mandibular growth which results in normal to slightly excessive mandibular growth. This can be used as a tool for early prediction of mandibular growth pattern that necessitates immediate intervention. Hence early correction of transverse maxillary deficiency and palatal displacement of maxillary lateral incisors can be regarded as a valuable aid in the prevention and treatment of skeletal mandibular deficiency in the growing stage as the mandible can be carried forward to its normal position. This can significantly shorten the treatment duration by possibly avoiding or simplifying a second phase treatment. Future studies will be needed to evaluate the effects of rapid maxillary expansion on mandibular growth in skeletal Class II malocclusion.

\section{REFERENCES}

1. Baccetti T, Franchi L, McNamara JA Jr, Tollaro I. Early dentofacial features of Class II malocclusion: a longitudinal study from the deciduous through the mixed dentition. Am J Orthod Dentofacial Orthop 1997;111:502-9.

2. Dewel, B.F.: Objectives of mixed dentition treatment in orthodontics. Am. J. Orthod., Dentofacial Orthop 1964; 50:504-20.

3. Franchi L, Baccetti T. Transverse maxillary deficiency in Class II and Class III malocclusions: a cephalometric and morphometric study on posteroanterior films. Orthod Craniofacial Res 2005; 8:21-8.

4. Garib DG, Henriques FC, Carvalho PEG; Gomes SC. Longitudinal Effects of Rapid Maxillary Expansion-A Retrospective Cephalometric Study. Angle Orthodontist 2007;77:442-448.

5. Guest SS, McNamara JA Jr, Baccetti T, Franchi L. Improving Class II malocclusion as a side-effect of rapid maxillary expansion: a prospective clinical study. Am J Orthod Dentofacial Orthop. 2010 Nov; 138(5):582-91.

6. Haas AJ. Palatal expansion : Just the beginning of dentofacial orthopedics. Am J Orthod Dentofacial Orthop 1970;57(3): 219-255.

7. Haas AJ. Entrevista: Dr. Andrew J. Haas. R Dental Press Ortodon Ortop Facial 2000;6:1-10.

8. Ionescu E, Teodorescu E, Badarau A, Grigore R, Popa M. Prevention perspective in orthodontics and dento-facial orthopedics. Journal of Medicine and Life., 2008; 1(4): 397-402.

9. King GJ, Keeling SD, Hocevar RA, Wheeler TT. The timing of treatment for Class II malocclusions in children: a literature review. Angle Orthod. 1990 Summer;60(2):87-97.

10. Kirjavainen M, Kirjavainen T, Haavikko K. Changes in dental arch dimensions by use of an orthopedic cervical headgear in Class II correction. Am J Orthod Dentofacial Orthop. 1997;111: 59-66.

11. Lima Filho RM, De Oliveira Ruellas AC. Mandibular behavior with slow and rapid maxillary expansion in skeletal Class II patients. Angle Orthod 2007;77:625-31. 
12. Lima RMA, Lima AL. Case report: long-term outcome of Class II division 1 malocclusion treated with rapid palatal expansion and cervical traction. Angle Orthod. 2000;70:89-94

13. Lione R, Brunelli V, Franchi L, Pavoni C, Quiroga Souki B, Cozza P. Mandibular response after rapid maxillary expansion in class II growing patients: a pilot randomized controlled trial. Prog Orthod. 2017 Nov 6;18(1):36.

14. Marshall S, Southard K, Southard T. Early transverse treatment. Semin Orthod 2005;11:130-9.

15. McNamara, JA.: Components of Class II malocclusion in children 8-10 years of age. Angle Orthod.,51:177-202, 1981.

16. McNamara JA. Maxillary transverse deficiency. Am J Orthod Dentofacial Orthop. 2000; 117:567-570.

17. McNamara JA Jr. Early intervention in the transverse dimension: is it worth the effort? Am J Orthod Dentofacial Orthop 2002;121: 572-4.

18. Mossey PA. The heritability of malocclusion: Part 1--Genetics, principles and terminology. Br J Orthod. 1999 Jun;26(2):103-13.

19. Patel Z, Ifzah, Habibullah S. Genetics in Orthodontics: a review. Eur J Pharmax Med Res., 2016,3(7), 539-545.

20. Proffit WR, Fields HW Jr, Sarver DM. Contemporary orthodontics. St. Louis (MO): Elsevier Health Sciences; 2014. p. 3-21.
21. Rita NS, Sadat MS. Growth modification in Class II malocclusion: a review. Updat Dent. Coll .j 2014;4(2):23-26

22. Sarver D, Johnston M. Skeletal changes in vertical and anterior displacement of the maxilla with bonded rapid palatal expansion appliances. Am J Orthod Dentofacial Orthop 1989;95:462-6.

23. Starnbach H, Bayne D, Cleall J, Subtelny JD. Facioskeletal and dental changes resulting from rapid maxillary expansion. Angle Orthod. 1966; 36(2):152-164.

24. Tollaro I, Baccetti T, Franchi L, Tanasescu CD. Role of posterior transverse interarch discrepancy in Class II, Division 1 malocclusion during the mixed dentition phase. Am J Orthod Dentofacial Orthop 1996;110:417-22.

25. Vargervik K. Morphologic evidence of muscle influence on dental arch width. Am J Orthod 1979;76:21-8.

26. Volk T1, Sadowsky C, Begole EA, Boice P. Rapid palatal expansion for spontaneous Class II correction. Am J Orthod Dentofacial Orthop. 2010 Mar;137(3):310-5.

27. Wendling LK. Short-Term Skeletal and Dental Effects of the Acrylic Splint Rapid Maxillary Expansion Appliance [master's thesis]. Ann Arbor, Mich: The University of Michigan; 1997.

28. Wertz RA. Skeletal and dental changes accompanying rapid midpalatal suture opening. Am J Orthod 1970;58:41-65. 